\title{
Review \\ Matrix Acidizing in Carbonate Formations
}

\author{
Ofelia Gomez Chacon and Maysam Pournik *iD
}

Department of Mechanical Engineering, University of Texas Rio Grande Valley, Edinburg, TX 78539, USA; ofelia.gomezchacon01@utrgv.edu

* Correspondence: Maysam.pournik@utrgv.edu; Tel.: +1-(956)-665-7488

\begin{abstract}
Matrix acidizing in carbonate reservoirs is a process that has been long used to increase productivity in oil and gas producing formations. The main goal is to create wormholes that bypass the damage in the formation. Hydrochloric acid $(\mathrm{HCl})$ is the main acid used for this; however, it has several disadvantages that affect the success of these treatments. Its high reaction rate, inability to divert, and corrosive nature are a few of the reasons why research in this area has focused on finding alternative fluids. This paper discusses studies on successful alternatives to $\mathrm{HCl}$. It has been observed that emulsified acids, which work with the addition of a surfactant to $\mathrm{HCl}$, have shown positive results as their high viscosity allows them to retard the reaction rate between the acid and the rock and form effective and dominant wormholes. This is needed, especially in hightemperature environments. As $\mathrm{HCl}$ also lacks the ability to divert to low-permeability zones in highly heterogeneous formations, emulsified acids are also helpful for this task. While viscoelastic surfactants have been found to be less susceptible to form damage since they do not have any polymer content, their diversion performance has not been as effective as emulsified acids. Corrosion is one of the greatest and most expensive issues faced in matrix acidizing treatments. The use of corrosion inhibitors has been proposed as the best way to deal with this problem. Inorganic corrosion inhibitors are no longer an option as they are extremely toxic and pose a great danger to the environment. Organic corrosion inhibitors have been proposed as an alternative since the 1970s. However, organic compounds still pose a hazard in their use. Natural extracts as alternatives have been proposed for their inhibition ability. The use of henna extract and aqueous garlic peel extract as corrosion inhibitors has shown positive results with lower corrosion rates compared to some conventional inhibitors.
\end{abstract}

Keywords: acidizing; matrix; diversion; corrosion

Formations. Processes 2022, 10, 174.

https://doi.org/10.3390/pr10010174

Academic Editor: Evangelos Tsotsas

Received: 16 December 2021

Accepted: 12 January 2022

Published: 17 January 2022

Publisher's Note: MDPI stays neutral with regard to jurisdictional claims in published maps and institutional affiliations.

Copyright: (c) 2022 by the authors. Licensee MDPI, Basel, Switzerland. This article is an open access article distributed under the terms and conditions of the Creative Commons Attribution (CC BY) license (https:// creativecommons.org/licenses/by/ $4.0 /)$.

\section{Introduction}

Acid stimulation of reservoir formations has been used for more than 100 years when Herman Frasch of Standard Oil patented the use of hydrochloric acid to stimulate carbonate formations [1]. Matrix acidizing consists of pumping acid into the wellbore at a pressure that is lower than the fracturing pressure. This leads to the creation of wormholes that occur because of the reaction of the acid with the rocks in the matrix and bypass the damage of the formation. The main goal of matrix acidizing is to restore and improve the formation's productivity by removing the near-wellbore damage and creating flow channels (wormholes) in carbonate formations [2]. Several factors must be considered in the process of choosing an adequate acid, for instance, temperature, pressure, crude composition, formation permeability, acid/crude compatibility, acid/additive compatibility, and compatibility between additives. As the injected acid generally travels to the high permeability (thief) zones of target formations, the use of diverters has been found crucial in the matrix acidizing process. These agents divert the acid to the less permeable, untreated zones by blocking the space through which the acid would usually go.

Rules and criteria that ease the selection process of adequate fluids and additives for the matrix acidizing have been proposed [3]. The first stage in the process is the pre-flush, which is a step prior to the main acid injection and its target is to minimize emulsions and 
precipitations in the formation. The next stage is the main acid injection, which is usually handled with hydrochloric acid $(\mathrm{HCl})$ on carbonate formations because of its considerable low cost and easy reactions with carbonate rocks like calcite, siderite, and dolomite. The preceding stage is the diversion stage (usually in a matrix acidizing process, there is an alternation of main acid injection and diverting agents which improves efficiency), where the diverting agent is injected to direct the acid to the untreated/less permeable zones of the formation. Lastly, the post-flush stage can easily be explained as the "washing-out stage" because of the following cleaning purposes: to get rid of the leftovers from the unutilized fluids from the previous stages. The compatibility between all the additives used and the fluids injected with the formation's mineralogical composition has been highly remarked in all recent studies. Despite matrix acidizing treatments not being able to mitigate all the damage in the formation, it is a valuable technique in removing some of the damage [4].

Within this century and the last, the most commonly used acid in matrix acidizing has been hydrochloric acid. This acid presents good effectiveness on carbonate formations because of its high dissolution of the formation's damage and its low cost. Nevertheless, studies have revealed several issues regarding the use of $\mathrm{HCl}$. One issue is the high reaction rates of $\mathrm{HCl}$, especially at high-temperature and high-pressure (HT/HP) conditions, which consequently results in higher volumes of acid used in matrix acidizing. In addition, the need of expensive corrosion inhibitors because of $\mathrm{HCl}^{\prime}$ s high corrosivity rates results in a not cost-effective solution. Hence, the search for $\mathrm{HCl}$ alternatives has been a major research focus in petroleum engineering studies. Such studies have attempted to give possible replacements for $\mathrm{HCl}$ in matrix acidizing treatments for carbonates that have the same positive properties as $\mathrm{HCl}$ but with lower reaction and corrosion rates.

In matrix acidizing, the production of single and dominant wormholes is preferred. Previous experimental studies in this area have shown the existence of an optimal acid injection rate at which maximum wormholing efficiency is produced [5-8]. Hence, the purpose of many laboratories' research focuses on finding this optimal injection rate, which could be defined as the injection rate that would produce the best wormhole with the lowest volume of acid. An optimal injection rate is found from laboratory experiments by determining the pore volume to breakthrough (PVBT) on the tested cores, which refers to how many times the volume of the core is needed for the acid to penetrate the core. Low optimal injection rates that require lower PVBT and further produce efficient wormholes are required for new acid systems. In addition to this, in heterogeneous formations where there is a contrast in the permeability of the rock, the acid tends to flow through the most permeable zone first, and leaves the less permeable zone of the formation untreated. This is a problem that must be properly addressed as one of the main goals of matrix acidizing is to raise the overall permeability of the formation. The use of diverters has been found to be crucial in acid stimulations, as it allows the acid to penetrate more uniformly. Chemical diverters like viscoelastic surfactants (VES) are preferred over mechanical diverters like ball sealers since the latter results to be more expensive.

Steel is the most common wellbore material in acidizing treatments, due to its costeffectiveness and good mechanical properties. However, it is very prone to damage due to the corrosive environment resulting from the use of $\mathrm{HCl}$ in acid stimulations. It can cause potential failure and represent great economic losses to oil and gas companies [9]. Despite the development of corrosion-resistant alloys (CRAs), the use of carbon steels is preferred. However, they are highly prone to corrosion in acidic environments, so the use of corrosion inhibitors is critical in these treatments. The use of organic compounds over inorganic compounds was presented as an alternative after the mid-1970s to mitigate corrosion due to the presence of $\mathrm{N}, \mathrm{S}$, and $\mathrm{O}$ heteroatoms, as the presence of lone pair electrons on these heteroatoms allows efficient absorption on a metallic surface [10]. Therefore, most of the studies in the literature have focused on the use of synthetic organic compounds as corrosion inhibitors. Greener alternatives have also been studied, such as the use of natural extracts as corrosion inhibitors. 
This review aims to summarize and compare the various studies of promising acids for matrix acidification. The first section will focus on various acid alternatives that lower reaction rates and enhance wormhole efficiency for high-temperature conditions. The second section will discuss positive acid alternatives that provide an effective diversion. The last section will provide data on several effective corrosion inhibitors with minimal environmental concerns and health risks. This review brings together all the different fluid developments for carbonate matrix acidizing within one paper in order to make it simpler for the decision-making process and future research plans. The paper focuses on the following three of the most common challenges in carbonate matrix acidizing that have required fluid developments: acid retardation for HPHT conditions, diversion for heterogeneous formations, and corrosion control for corrosive environments.

\section{High-Temperature Conditions}

The use of hydrochloric acid has two major problems at high temperatures that will be further discussed in this section:

(1) High acid volume required: Due to the fast chemical reaction rate of $\mathrm{HCl}$ with formations, acid is consumed quickly, resulting in the use of higher volumes of acid in acidizing treatments. This issue is worsened in high-temperature formations, as an increase in temperature increases the rate of reaction (as the Arrhenius reaction rate theory states: "a rise in temperature of $10^{\circ} \mathrm{C}$ will roughly double the rate of a chemical reaction") [11] through increasing the average kinetic energy of the reactant.

(2) Inefficient wormhole structure: $\mathrm{As} \mathrm{HCl}$ reacts quickly with the formation, it does not have enough time to penetrate deep into the media and leads to more uniform dissolution. It also does not provide an effective production of wormholes. Furthermore, it has been found that lowering the injection rate at high temperatures to increase contact time results in face dissolution, which is not an efficient structure for acidizing treatments.

Extensive studies have shown that higher volumes of acid are required, and more uniform dissolutions occur due to the faster reaction rates as formation temperature increases, hence the need for new acid formulations to overcome these issues. In Table 1, it can be seen how the injection of $\mathrm{HCl}$ at a temperature of $394.26 \mathrm{~K}$ and at an injection rate of $3.3 \times 10^{-8} \mathrm{~m}^{3} / \mathrm{s}$ resulted in a conical channel and dissolution of the core face [12]. Moreover, it required a PVBT of 4.25, which is relatively high. Furthermore, as the acid is spent quicker at high temperatures, higher optimal injection rates [13] are required for an effective acidizing treatment. In high-temperature environments, the need for an acid that retards the acid reaction, requires lower injection rates, leads to dominant wormholes, and lowers corrosion rates, is the main priority. As a result, there has been significant work to develop acid systems that address these concerns.

\subsection{Organic Acids}

The use of organic acids was one of the first proposed alternatives to $\mathrm{HCl}$. This is because of their lower dissolution rates compared with $\mathrm{HCl}$. The organic acids provide a deeper penetration as they spend less time on the rock and penetrate deeper into the formation compared to $\mathrm{HCl}$ [14]. The most common examples of organic acids are acetic and formic acid; however, there are more effective organic acids like methanesulfonic acid (MSA).

\subsubsection{Acetic Acid}

At a temperature of $394.26 \mathrm{~K}$, a study [15] reported a PVBT of 9.1 at an injection rate of $2.2 \times 10^{-8} \mathrm{~m}^{3} / \mathrm{s}$ with the use of $15 \%$ acetic acid (HAc). Moreover, its wormhole structure shows a dominant wormhole, but with some branches (see Table 1). Nevertheless, the cost of organic acids has been found to be higher than the cost of $\mathrm{HCl}$ for the same mass of rock dissolved [13]. The high value of PVBT from acetic acid is due to the low dissolving power of this weak acid. Buijse et al. [16] argued that while $100 \%$ of $\mathrm{HCl}$ was spent after 
the rock-acid reaction was completed, only $54 \%$ of acetic acid was spent. In addition to this, organic acids like acetic and formic have to be used at careful concentrations to avoid calcium acetate and calcium formate precipitation. Low dissolving capacity has been shown to be an issue with the use of organic acids, which limits their wormhole production capacity, thus resulting in weak acidizing treatment [17].

\subsubsection{Methanesulfonic Acid}

Methanesulfonic acid has been proposed as a standalone stimulation fluid [18], as its acidity is higher than other organic acids like acetic and formic, therefore making it a stronger organic acid. MSA also addresses most issues with organic acids, as it has soluble reaction products, lower corrosivity, and low toxicity. However, it is very expensive. An experimental study [12] was conducted with the purpose of finding the optimal acid blend of $\mathrm{HCl}$ and MSA, which would result in a more cost-effective acid system than using MSA by itself. This experiment tested HCl:MSA acid blends of 2.5:7.5, 5:5, and 7.5:2.5 wt\% $\mathrm{HCl}: M S A$ at injection rates of $3.3 \times 10^{-8}, 8.3 \times 10^{-8}, 1.3 \times 10^{-7}$, and $1.7 \times 10^{-7} \mathrm{~m}^{3} / \mathrm{s}$ at a temperature of $394.26 \mathrm{~K}$. The optimum acid blend was 5:5 wt \% HCl:MSA, which at its optimal injection rate of $1.3 \times 10^{-7} \mathrm{~m}^{3} / \mathrm{s}$, required a PVBT of 1.33 . The acid blend produced a single, straight, and dominant wormhole (Table 1 ).

\subsection{Surfactant-Based Emulsified Acids}

Retarded acid systems usually add a retarding agent to $\mathrm{HCl}$ to retard its diffusion to the carbonate surface and allow a deeper penetration of the live acid [2]. One example of this is emulsified acids that are an effective alternative to the shortcomings of $\mathrm{HCl}$, especially because they result in better acid distribution because of their higher viscosity [4]. In addition to this, because of their higher viscosity, they result in lower reaction rates than $\mathrm{HCl}$. Emulsified acids usually work with the addition of a surfactant to the acid solution. The most used surfactants in the literature are nonionic and cationic surfactants. Nonionic surfactants consist of a neutral charge on their hydrophilic end, while cationic surfactants have a positive charge instead. While cationic surfactants are the most used, nonionic surfactants are said to be more promising since they do not pose any incompatibilities with other additives or surfactants and are soluble in water [4].

\subsubsection{Cationic Surfactant-Based Polymer-Assisted Emulsified Acid}

The use of cationic surfactants has been widely studied, but they have resulted in the formation of corrosion products $\left(\mathrm{Fe}^{+2}\right)$ due to incompatibility [3]. However, Zakaria \& Nasr-El-Din, 2016 [19], have shown positive results with the use of a cationic surfactant in a polymerassisted emulsified acid system (this acid system will be referred to as PA EA). The main objective of that study was to combine the benefits of gelled and emulsified acids into one by the addition of $(1.5 \%)$ polymer to the internal acid phase. This action was expected to reduce the diffusion of the acid droplets, thus retarding its reaction rate by increasing the viscosity of the acid. Such an acid system resulted in a stable acid (no phase separation after 3 days) with non-Newtonian shear-thinning behavior. At low injection rates of $8.3 \times 10^{-9} \mathrm{~m}^{3} / \mathrm{s}$, this acid system had a PVBT of 1.81 , and at intermediate injection rates of $3.3 \times 10^{-8}$ and $8.3 \times 10^{-8} \mathrm{~m}^{3} / \mathrm{s}$, it achieved a smaller PVBT of 0.34 and 0.38 , respectively (see Table 1). Furthermore, it can be observed in Table 1 how this acid system resulted in a dominant wormhole. Some branching can also be observed, but the core inlet and outlet observed in Table 1 show that there was only one dominant wormhole that achieved penetration at both the inlet and the outlet. Since some polymer can remain inside the formation and lead to further damage in the formation (plugging), a mutual solvent was used in the post-flush phase of the system, getting rid of most of the polymer residue. 


\subsubsection{Non-Ionic Surfactant-Based Emulsified Acids}

The application of nonylphenol has been proposed as a non-ionic surfactant in an emulsified acid (this acid system will be referred to as NP 100 EO) [20]. Experimental data demonstrated that the addition of nonylphenol with a high degree of ethoxylation reduces the reaction rate of $\mathrm{HCl}$, with the reaction time increasing from $10 \mathrm{~s}$ to $1027 \mathrm{~s}$. Such behavior is due to the increase in viscosity (which increased from $1.307 \times 10^{-3}$ Pa.s to $7.987 \times 10^{-3}$ Pa.s) by the addition of this non-ionic surfactant, since viscosity is highly dependent on the degree of ethoxylation. It can be observed in Table 1 that NP 100 EO had a lower pore volume to breakthrough at the same injection rate of $\mathrm{HCl}$ because of its delayed reaction. Additionally, NP $100 \mathrm{EO}$ resulted in a dominant wormhole at a low flow rate $\left(8.3 \times 10^{-9} \mathrm{~m}^{3} / \mathrm{s}\right)$, while at the same flow rate, $\mathrm{HCl}$ resulted in face and conical dissolution (see Table 1). Unfortunately, this study was conducted at a temperature of 298.15 K. Nevertheless, because of NP 100 EO's low dissolution rate and the formation of effective wormholes at low injection rates (which curtails the need for high acid volumes), it presents potential characteristics that could be further studied in high-temperature environments. Another non-ionic surfactant with a high degree of ethoxylation also led to the formation of a stable emulsion, up to a temperature of $422.04 \mathrm{~K}$ [4]. This emulsified acid (which will be referred to as NIS-EA) was investigated for its application in HT/HP wells. It required a low PVBT of 0.19 at a low injection rate of $3.3 \times 10^{-8} \mathrm{~m}^{3} / \mathrm{s}$ for a carbonate core. In addition to this, it also resulted in a dominant wormhole (Table 1).

\subsection{Especialized Gelled Acid}

Gelled acids are another type of retarded acid. They work with the addition of polymer to the acid. According to the literature, modifications to gelled acids have been necessary for effective stimulation. One example of this is in-situ gelled acids that work with the addition of a crosslinker to the gelled acid. Without the addition of this, gelled acids result in filter cakes, and this was observed to be detrimental to the permeability enhancement in core flooding experiments [21]. The use of in-situ gelled acids forms a thin layer of gel that minimizes the leak-off, preventing the buildup of polymer filter cake [21]. Other modifications to gelled acids have been studied in the literature.

\section{Biopolymeric Resin-Based Retarded $\mathrm{HCl}$}

A study [13] proposed a retarded $\mathrm{HCl}$ acid system that works with the addition of a biopolymeric resin-based composite (this will be referred to as BP Retarded $\mathrm{HCl}$ ) that "restricts the proton mobility of the acid species and hence reduces its reaction rate towards any substrate". Experiment results showed that the optimum injection rate at a temperature of $394.26 \mathrm{~K}$ was $4.2 \times 10^{-8} \mathrm{~m}^{3} / \mathrm{s}$ and the resulting PVBT was 0.41 , as shown in Table 1 . It was further stated that the calcium concentration of the effluent samples was lower than the previous tests $(70,000 \mathrm{ppm})$, which indicated that the acid had the ability to penetrate deeper into the cores. In addition to this, it can be observed in Table 1 how this acid system also resulted in the production of a single dominant wormhole on the core at a low injection rate of $4.2 \times 10^{-8} \mathrm{~m}^{3} / \mathrm{s}$. 
Table 1. Experimental characteristics and results from core flooding experiments from different acid systems at high temperatures.

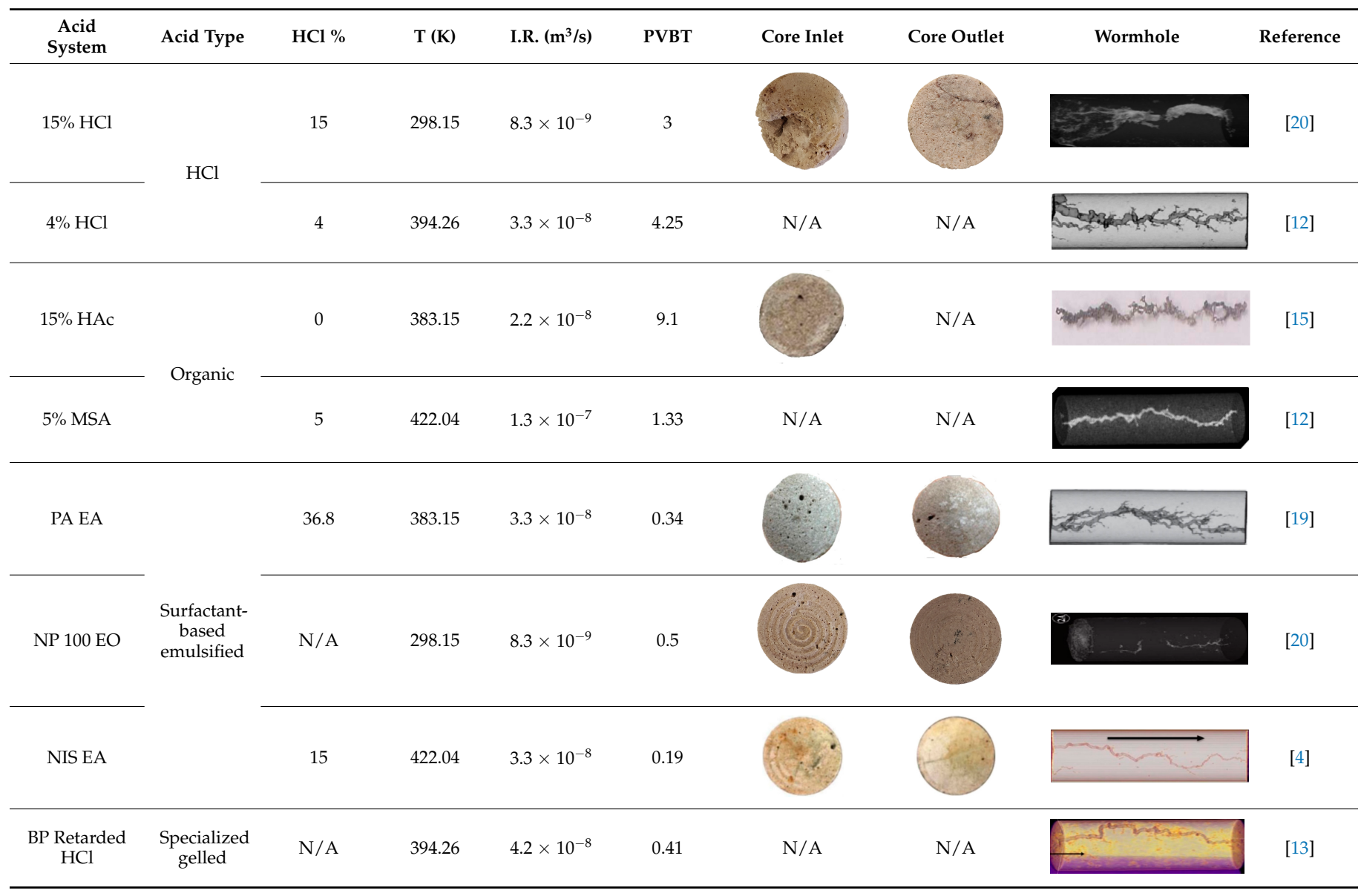

When comparing the results from the high temperatures, NIS-EA is the acid system that had the lowest value of PVBT at a fairly low injection rate. These are good results because the temperature at which the experiment was performed was quite high (422.04 K). This acid system also had a dominant wormhole with almost no branches. The use of the MSA: $\mathrm{HCl}$ blend also had good results when compared to the 15\% HAc acid system, as it required a lower PVBT. However, it was not the lowest PVBT in this section, and it had the highest optimal injection rate of all the acids discussed. The PA EA also had good results, but when compared to the wormhole of NIS-EA, it had more branches, as is also the case with 15\% HAc. The BP Retarded $\mathrm{HCl}$ system also had good PVBT at an injection rate of $4.2 \times 10^{-8} \mathrm{~m}^{3} / \mathrm{s}$ and at a high temperature of $394.26 \mathrm{~K}$. NP $100 \mathrm{EO}$ also had effective results, since at low injection rates it had better performance than that of $\mathrm{HCl}$; however, it should be further tested at different temperatures.

\section{Heterogenous Formations}

As stimulation treatments have the purpose of raising the overall permeability of the formation, the heterogeneity of multiple layers is a concerning issue for matrix acidizing treatments in carbonate formations [22,23]. Hence, acid diversion is an indispensable and successful practice to stimulate carbonate reservoirs. There are two outstanding challenges, as detailed in the following:

(1) Pure $\mathrm{HCl}$ cannot achieve diversion: This issue is worsened in highly heterogeneous formations and thick reservoirs since large permeability contrast can significantly reduce the overall efficiency of stimulation treatments [24]. This can be seen in Table 2, where in a dual core flooding experiment, even at a low-permeability contrast, $\mathrm{HCl}$ reached breakthrough only through the high-permeability core [25]. 
(2) Polymers used with acid tend to cause damage: This inhibits wormhole growth and can even cause the overall permeability of the core to decrease [24].

The best way to achieve a uniform acid distribution is by using acid diverters. They are crucial for an effective acid treatment. Mechanical diverters include techniques like coiled tubing and bull heading, and despite their effectiveness, the use of chemical diverters is preferred. The use of diverting agents has been proposed since 1936, when oil-soluble calcium soap was proposed as the first diverting agent for acidizing treatments [26]. These agents can temporarily plug the high-permeability zones of the formation, thus diverting the fluid to the low-permeability zones. In recent years, the use of diverting acids like emulsified and foam-based acids has been found to be successful [27]. Thus, the use of self-diverting agents (SDA) like in-situ crosslinked acid (ICA) and viscoelastic diverting agents (VDA) has been widely studied for their beneficial characteristics. In laboratory experiments, the diversion capability of acids at a specific permeability contrast can be studied in dual core flooding experiments (where acid can be injected into two cores simultaneously). This is beneficial because it is possible to see if the acid will be diverted to the lower permeability core at this permeability contrast (KR). Permeability contrast is represented as the permeability ratio between the high-permeability and low-permeability cores. This section will specifically discuss different diversion acid systems based on their dual core flooding experiment results and the permeability enhancement of the lower permeability core.

\subsection{Polymer-Assisted Emulsified Acid}

The use of emulsified and gelled acids has previously been found successful in matrix acidizing systems [28-30]. The PA EA (polymer-assisted emulsified acid) system that was discussed in the previous section combined the usefulness of both acids that showed the ability to viscosify and retard the dissolution rate of the acid in the system by the addition of $1.5 \%$ polymer to the internal phase of the acid [19]. PA EA was used to test the selfdiverting ability of the system. Results show that at an injection rate of $1.7 \times 10^{-8} \mathrm{~m}^{3} / \mathrm{s}$ and KR of 19, the acid was able to divert to the low-permeability core. Furthermore, the low-permeability core did not show any pressure drop with the pressure transducers used, which was inferred to mean infinite permeability enhancement. For this experimental study, there were no core inlet and outlet pictures, but the CT scan of the wormhole generated on the low-permeability core and the one that was generated on the high-permeability core are shown in Table 2. Here, the acid was able to enter the high-permeability core, but not at its full length, as it was diverted to the low-permeability core, achieving a dominant wormhole along the full length of the low-permeable core. Furthermore, it was previously mentioned that one of the problems with gelled acids is the polymer-retention at the core face, resulting in permeability damage. In these experiments, mutual solvent was injected to remove any damage and ensure permeability enhancement was achieved.

\subsection{Viscoelastic Surfactant-Based Acid}

As it was previously explained, the use of gelled acids can cause polymer retention on the core face and can reduce the overall permeability. The VDA acid systems are very beneficial in this matter, as they do not have any polymer content. The properties of VDAs have been in the scope of many experimental studies that seek to find the most adequate diverting agent for adverse reservoir conditions like low-permeability, high temperatures, and highly heterogeneous formations. The addition of viscoelastic surfactants (a type of VDA usually referred to as VES) to $\mathrm{HCl}$ has been proven to lower the dissolution rate of the acid because VES is able to self-viscosify, thus lowering the contact of $\mathrm{H}^{+}$ions with the rock. Further benefits from this acid include its selectivity to low-permeability zones and its sensitivity to crude oil, which is beneficial in high water cut formations, where previous acidizing treatments resulted in an increase in water production. 


\subsubsection{TN-16235}

The effectiveness of the viscoelastic surfactant named TN-16235 was discussed in a study, where it was used as an acid treatment that would not increase the water cut after acidizing [31]. This surfactant was able to divert the fluid away from the water-saturated zone and into the hydrocarbon-saturated zone. The removal of TN-16235 was done by using a mutual solvent and a microemulsion at the end of the treatment. It can be seen in Table 2, that the use of TN-16235 resulted in a permeability increase of $6256.6 \%$ on the low-permeability core at KR of 13.1. When looking at the core images in Table 2, the acid penetrated both the inlet and the outlet of the low-permeability core, but no penetration can be seen in the high-permeability core, showing that the acid was able to divert to the low-permeability core. For higher permeability contrast environments, a foam-based viscoelastic surfactant has been introduced that combines the plugging ability of a foam acid and the high viscosity of VES [27]. As stated before, effective plugging is necessary to temporarily block the high-permeability zone and direct the fluid to the low-permeability area.

\subsubsection{VES and Foam-Based VES}

A detailed study compared the behavior of foam acid, pure VES, and foam-based VES in parallel core flood tests with a large permeability contrast [27]. The foam acid was used in these experiments with the purpose of comparing it to the behavior of foam-based VES. The ineffectiveness of foam acid by itself in highly heterogeneous formations was one of the conclusions of this study, since it was effective but only up to a KR of 7.8, where it resulted in a permeability increase of $13.1 \%$ for the low-permeability core. There were no core images at this KR; however, in Table 2, it can be observed the core images of low and high-permeability cores when KR is 9.8 with no visible penetration on the core outlet of the low-permeability core. The pure VES showed good results at a KR of 9.8 (with a permeability increase of $39.2 \%$ for the low-permeability core), but at a KR of 12.3 (see in Table 2), it ceased to be effective as there was only penetration on the core inlet and outlet of the high-permeability core with no penetration on the low-permeability core. It can be observed that the foam-based VES had a higher oil phase permeability enhancement in the low-permeability core (54.3\%) than the three acids studied at the KR of 14.8. However, none of the acids tested were able to achieve diversion at the KR of 16.8. 
Table 2. Permeability increase on low-permeability cores after different acid treatments.

\begin{tabular}{|c|c|c|c|c|c|c|c|c|c|c|c|}
\hline $\begin{array}{c}\text { Acid } \\
\text { System }\end{array}$ & Acid Type & $\mathrm{HCl} \%$ & $\begin{array}{c}\mathrm{T} \\
(\mathrm{K})\end{array}$ & KR & $\begin{array}{c}\text { I.R. } \\
\left(\mathrm{m}^{3} / \mathrm{s}\right)\end{array}$ & PVBT & $\begin{array}{l}\mathrm{Ko} \\
\left(\mathrm{m}^{2}\right)\end{array}$ & $\underset{\left(\mathbf{m}^{2}\right)}{\mathbf{K f}}$ & $\begin{array}{c}\text { Low- } \\
\text { Permeability } \\
\text { Core }\end{array}$ & $\begin{array}{c}\text { High- } \\
\text { Permeability } \\
\text { Core }\end{array}$ & Reference \\
\hline & & & & & & & & & $\begin{array}{l}\text { Core Inlet I } \\
\text { Core Outlet }\end{array}$ & $\begin{array}{l}\text { Core Inlet I } \\
\text { Core Outlet }\end{array}$ & \\
\hline $15 \% \mathrm{HCl}$ & Mineral & 15 & 293.15 & 1.1 & $8.3 \times 10^{-9}$ & $\mathrm{~N} / \mathrm{A}$ & $5.7 \times 10^{-14}$ & $8.2 \times 10^{-14}$ & & & [25] \\
\hline PA-EA & $\begin{array}{l}\text { Surfactant- } \\
\text { based } \\
\text { emulsified }\end{array}$ & 36.8 & 383.15 & 19 & $1.7 \times 10^{-8}$ & N/A & $3.0 \times 10^{-15}$ & infinite & & & [19] \\
\hline TN-16235 & \multirow{4}{*}{$\begin{array}{l}\text { Viscoelastic } \\
\text { surfactant- } \\
\text { based } \\
\text { emulsified }\end{array}$} & 15 & 393.15 & 13.1 & $8.3 \times 10^{-9}$ & 0.65 & $3.0 \times 10^{-15}$ & $1.9 \times 10^{-13}$ & & & [31] \\
\hline Pure VES & & 15 & 333.15 & 9.8 & $2.5 \times 10^{-8}$ & 3.42 & $2.0 \times 10^{-14}$ & $2.8 \times 10^{-14}$ & N/A & N/A & [27] \\
\hline Pure VES & & 15 & 333.15 & 12.3 & $2.5 \times 10^{-8}$ & N/A & $1.5 \times 10^{-14}$ & $1.6 \times 10^{-14}$ & & & [27] \\
\hline $\begin{array}{l}\text { Foam- } \\
\text { based } \\
\text { VES }\end{array}$ & & 15 & 333.15 & 15 & $2.5 \times 10^{-8}$ & 2.74 & $1.5 \times 10^{-14}$ & $2.4 \times 10^{-14}$ & & N/A & [27] \\
\hline $\begin{array}{c}\text { Foam } \\
\text { acid }\end{array}$ & \multirow{2}{*}{ Foam } & 15 & 333.15 & 7.8 & $2.5 \times 10^{-8}$ & $\mathrm{~N} / \mathrm{A}$ & $1.5 \times 10^{-14}$ & $1.7 \times 10^{-14}$ & N/A & $\mathrm{N} / \mathrm{A}$ & [27] \\
\hline $\begin{array}{l}\text { Foam } \\
\text { acid }\end{array}$ & & 15 & 333.15 & 9.8 & $2.5 \times 10^{-8}$ & N/A & $1.4 \times 10^{-14}$ & $1.5 \times 10^{-14}$ & & & [27] \\
\hline
\end{tabular}

As $\mathrm{HCl}$ is not able to divert itself to the least permeable zones in the formations even at low-permeability contrasts, the use of chemical diverters has been found successful in the experimental research presented in this section. Comparing the results, the use of viscoelastic surfactants showed an effective diversion. The foam-based VES had a higher permeability enhancement than the use of pure VES, achieving an increase of $54.3 \%$. The use of TN-16235, which is another type of VES, also achieved a large permeability increase of $6236.6 \%$. These results are due to the VES's ability to self-viscosify, thus lowering the dissolution rate of the acid. Another benefit of VES is that it does not have any polymer content and therefore is less probable to leave any damage on the formation. Despite having polymer content, the PA EA system has the highest performance out of all the fluids in this paper, resulting in an infinite permeability enhancement at the highest permeability contrast of 19.

\section{Corrosive Environments}

As the metallic materials in the equipment come into direct contact with the acid used (usually at concentrations of $5 \%$ to $28 \%$ ), it causes a high degree of corrosion to these materials [32]. Corrosion problems in oilfield applications represent an important economic significance to the total cost of oil and gas producing companies every year all over the world. According to a study conducted by the National Association of Corrosion Engineers (NACE) [9], total annual economic losses due to corrosion are around 2.5 trillion USD in the oil and gas industry. Hence, there is a strong financial need for corrosion control techniques, in addition to the desire to minimize potential damage to water resources, the environment, and life [32]. The following are the two main problems that have been identified in this matter:

(1) $\mathrm{HCl}$ has a pitting tendency on steel materials that can vary with $\mathrm{HCl}$ concentration [1]: It is not only $\mathrm{HCl}$, but even organic acids are equally corrosive [33]; however, are they shown to be easier to inhibit than mineral acids [10]. This problem is exacerbated in high-temperature environments as the general corrosion rate (CR) can increase exponentially with increasing temperature and acid concentration [32]. 
(2) Despite the effectivity of the use of inorganic corrosion inhibitors like arsenate or arsenic salt and antimony, they have been found to be extremely detrimental to human health and are toxic to the environment: Arsenic compounds were one of the first used corrosion inhibitors by J.A Gravell, because of their ability to form a protective coating on the metal surface. However, these compounds have been found to produce poisonous arsine gas in acidic environments [32], and a great number of people have died because of arsenic poisoning.

The study of the materials used in acidizing treatments is of great importance since corrosion affects the durability of these. Steel is the main component of pipelines in well construction. Their types can range from mild steel (API N80, L80, J55) to high Cr-content corrosion resistant alloys (austenitic-ferritic steel and modified martensitic 13\% Cr steel) [34,35]. Even though these corrosion-resistant alloys (CRA) have been developed to deal with corrosive environments, the use of carbon steels (CSs) has been preferred because of their low cost. As an example, austenitic stainless steels like AISI 304, cost eight times more than carbon steel [36]. It has been stated in the literature that the use of carbon steels (CSs) and an effective chemical treatment is the best budget-friendly method for corrosion control in acid treatments [37]. Without the proper chemical treatments, CSs are highly exposed to corrosion. The most used steel in downhole tubulars is API N80 CS [32]. Moreover, API L-80 grade CS has been reported as being $\mathrm{H}_{2} \mathrm{~S}$-resistant [38]. The steel composition of these materials may vary among manufacturers, but knowledge about their chemical composition is crucial for the selection of an appropriate corrosion inhibitor, so the study of their different chemical compositions is encouraged for corrosion control strategies. Some of these differences can be found in a recent review [32].

The use of corrosion inhibitors is the most efficient way to deal with corrosion. A corrosion inhibitor (CI) is a substance with the purpose of forming a protective film that provides protection from the corrosive medium [10] by decreasing the corrosion rate of the metallic material. However, a corrosion inhibitor is only effective for a specific metallic material and for a certain environment. It has been pointed out that the use of CI is the most cost-effective corrosion control for acidizing treatments. The selection of an adequate CI depends on the acid type and strength, the steel type, the desired protection time, and the temperature [39].

The purpose of this section is to discuss the inhibition capabilities of different organic and natural extract corrosion inhibitors. The main characteristics that will be identified are the corrosion inhibitor's optimal concentration and its corrosion rate (occurring at the inhibitor's optimal concentration), which can be observed from the scanning electron microscope (SEM) images of the material before and after the use of a corrosion inhibitor in a typical acidizing treatment. Inhibition efficiency (IE\%) was calculated by using the ratio of corrosion rate in the absence of the corrosion inhibitor minus the corrosion rate in the presence of the inhibitor over the corrosion rate in the presence of the inhibitor, multiplied by $100 \%$. The corrosion rates are compared to those of $\mathrm{HCl}$ on the same samples in the absence of the inhibitor. The corrosion rate is calculated by using weight loss measurements that provide more reliable results than electrochemical techniques because the experimental conditions more closely simulate real-life conditions. All experiments were conducted on steel coupons.

\subsection{Organic Corrosion Inhibitors}

Several corrosion inhibitors have been presented since the past century (a brief timeline of the evolution of corrosion inhibitors can be found in a recent review paper [40]). In 1928, arsenic compounds were one of the first corrosion inhibitors used because of their ability to form a protective coating on a metal surface. However, these compounds have been found to produce poisonous arsine gas in acidic environments [32], and a great number of people have died because of arsenic poisoning. Therefore, the use of inorganic compounds like arsenate or arsenic salt and antimony has been found to be extremely detrimental to human health and toxic to the environment. The use of organic compounds was presented 
as an alternative after the mid-1970s to mitigate corrosion due to the presence of N, S, and $\mathrm{O}$ heteroatoms, as the presence of lone pair electrons on these heteroatoms allows efficient absorption on a metallic surface [10]. The protective strength of heterocyclic compounds as corrosion inhibitors is due to the adsorption of the inhibitor molecules on active sites of the metallic surfaces. This was more specifically identified in synthetic compounds containing $\mathrm{N}$ and $\mathrm{S}$ atoms [41-44]. Therefore, most of the studies in the literature have focused on the use of synthetic organic compounds as corrosion inhibitors. Several types of organic compounds have been studied for their effectiveness as corrosion inhibitors, and it has been shown that each CI works only on specific types of steel and in certain environments. Therefore, empirical research must be done to determine the best type of CI for the given conditions. There are two excellent reviews of various organic corrosion inhibitors, the medium tested, the inhibitor concentration, and their resulting inhibitor efficiency [10,32]. The trend that has been observed among all studies is that as the corrosion inhibition concentration increases, the inhibition effectiveness on the steel coupons also increases [45-54].

In the following section, the inhibitive actions of some organic corrosion inhibitors in corrosive environments will be discussed. In Table 3, it can be observed that some of the corrosion inhibitors that have been studied in the literature, as well as their corrosion rates and the medium and concentration at which they were tested.

\subsubsection{Alcohol Based Inhibitors: Propargyl and Furfuryl Alcohol}

The molecules that contain nitrogen and acetylenic alcohols are observed to form a protective film on metal surfaces, and this retards the metal dissolution process [55]. Alcohols are widely used because of their effectiveness and low cost. Propargyl alcohol is the most used CI in the oil and gas industry, as well as its derivatives like cinnamaldehyde and nitrogen aromatic-based compounds. At a temperature of $373.15 \mathrm{~K}$, in the absence of the corrosion inhibitor, the corrosion rate of $15 \% \mathrm{HCl}$ is $3.9 \times 10^{-7} \mathrm{~m} / \mathrm{s}$ on MS. In contrast, a corrosion rate of $1.2 \times 10^{-9} \mathrm{~m} / \mathrm{s}$ in $15 \% \mathrm{HCl}$ on $\mathrm{MS}$ with the use of propargyl alcohol was reported at the same temperature [56]. This is an IE\% of $99.7 \%$.

Furfuryl alcohol is another example of an acetylenic alcohol. A study looked at the inhibition ability of furfuryl alcohol in N80 steel. The corrosion rate was calculated by weight loss measurements at temperatures ranging from 303.15 to $383.15 \mathrm{~K}$ in $15 \% \mathrm{HCl}$ after $1 \mathrm{~h}$ of immersion in the acid. The inhibition effectiveness was observed to increase with the temperature increase. The optimum concentration of furfuryl alcohol was identified as $15.7 \mathrm{~kg} / \mathrm{m}^{3}$, which was the concentration at which all the experiments were performed in this study. The corrosion rate was significantly reduced as in the absence of the corrosion inhibitor, the corrosion rate was $1.5 \times 10^{-8} \mathrm{~m} / \mathrm{s}$ at $303.15 \mathrm{~K}$ and $9.3 \times 10^{-7} \mathrm{~m} / \mathrm{s}$ at $383.15 \mathrm{~K}$. The corrosion rate with the use of furfuryl alcohol was $47.1 \%$ in $15 \% \mathrm{HCl}$ at $303.15 \mathrm{~K}$, which is an IE\% of $90.1 \%$ [45]. The corrosion rate in the absence of the corrosion inhibitor and with an increase in temperature notoriously increases. SEM micrographs are also displayed in this study (Table 3), where it can be seen that a compact layer of the inhibitor forms on the metal surface.

\subsubsection{Quinolin-5-Ylmethylene-3-\{[8-(Trifluoromethyl)Quinolin-4-Y1]Thio\}Propanohydrazide}

Heterocyclic compounds containing heteroatoms like nitrogen, oxygen, and sulphur have been identified as effective corrosion inhibitors in acidic media [48,57-64]. An experimental study synthesized an organic compound to test its corrosion inhibition behaviour [53]. The molecular design of this new compound is based on the fact that quinoline, which is a nitrogen heterocycle, would effectively inhibit corrosion in mild steel. This study tested the corrosion inhibitor (QMQTPH) at various temperatures (303.15-333.15 K), concentrations $\left(0.01-0.5 \mathrm{~kg} / \mathrm{m}^{3}\right)$ of the inhibitor, and after an immersion of $24 \mathrm{~h}$ in $3.1 \%$ and $6.2 \%$ of $\mathrm{HCl}$. The corrosion rate was reduced compared with that of $\mathrm{HCl}$ in the material with no corrosion inhibitor $\left(5.0 \times 10^{-10} \mathrm{~m} / \mathrm{s}\right.$ at $303.15 \mathrm{~K}$ in $\left.3.1 \% \mathrm{HCl}\right)$. The lowest corrosion rate was $3.5 \times 10^{-11} \mathrm{~m} / \mathrm{s}$ at $303.15 \mathrm{~K}$, at $0.5 \mathrm{~kg} / \mathrm{m}^{3}$ of the inhibitor in $3.1 \% \mathrm{HCl}$. 
This resulted in an IE\% of $93.1 \%$. It was noted that the corrosion rates were higher in the $6.2 \% \mathrm{HCl}$. The highest corrosion rate of $9.5 \times 10^{-10} \mathrm{~m} / \mathrm{s}$ was at $333.15 \mathrm{~K}, 0.01 \mathrm{~kg} / \mathrm{m}^{3}$ of the corrosion inhibitor in $6.2 \% \mathrm{HCl}$. Despite the high temperature $(333.15 \mathrm{~K})$, at a concentration of $0.5 \mathrm{~kg} / \mathrm{m}^{3}$, this inhibitor achieved a corrosion rate of $1.8 \times 10^{-10} \mathrm{~m} / \mathrm{s}$ in $3.1 \% \mathrm{HCl}$ and $3.1 \times 10^{-10} \mathrm{~m} / \mathrm{s}$ in $6.2 \% \mathrm{HCl}$. It was also observed that the corrosion rate increased with temperature and decreased with a rise in inhibitor concentration. The SEM micrographs shown in Table 3 were performed on mild steel in $3.1 \% \mathrm{HCl}$ before and after the application of QMQTPH. They show that after the application of QMQTPH, faceting resulting from the pits provoked by $\mathrm{HCl}$ disappears, which shows the effective inhibiting behavior of QMQTPH.

\subsection{Natural Extracts As Corrosion Inhibitors}

Even though great inhibition effectiveness (most IE in the mentioned organic corrosion inhibition reviews has been $>60 \%$ ) has resulted from the use of the most common organic inhibitors (i.e., aldehydes, acetylenic compounds, and thiourea derivatives), these inhibitors are still toxic, harmful to the environment, and non-biodegradable [10]. These have worried worldwide organizations that take care of environmental issues. One example of this is The Convention for the Protection of the Marine Environment of the North-East Atlantic (OSPAR Convention), whose target is to deal with the following specific areas:

- Annex I: Prevention and elimination of pollution from land-based sources.

- Annex II: Prevention and elimination of pollution by dumping or incineration.

- Annex III: Prevention and elimination of pollution from offshore sources.

- Annex IV: Assessment of the quality of the marine environment.

- Annex V: On the protection and conservation of the ecosystems and biological diversity of the maritime area.

These areas directly affect the oil and gas industry, and it has been stated in recent studies that most corrosion inhibitor formulations no longer satisfy the OSPAR Convention's requirements since their primary ingredients are extremely harmful if they come into contact with the environment [32]. Acetylenic and antimony compounds cause dangerous problems because of their high toxicity [65]. Hence, the need to develop a safer corrosion inhibitor formulation that satisfies the OSPAR Convention's requirements has been an important focus, especially since one of their ultimate goals was to "replace all hazardous chemical discharges by 2020" [66]. Several new categories of organic corrosion inhibitors have been introduced in the past years to satisfy these requirements, with natural extracts being the main focus; however, their use is still in the experimental stage with limited field applications [67-69].

\subsubsection{Henna Extract}

Despite their effectiveness, the hazards of most synthetic corrosion inhibitors are widely known [32]. Environmental regulations have forced researchers to look for greener alternatives. Natural extracts are one of the best options for this matter. Henna extract, an herb often used for its dying purposes in Asia and North Africa for centuries, has been studied since the past decade as a potential corrosion inhibitor. Its corrosion behavior in mild steel in $3.1 \% \mathrm{HCl}$ after $6 \mathrm{~h}$ of immersion was studied through polarization measurements and electrochemical impedance [67]. This study measured its corrosion rate at different concentrations of henna extract (from 0 to $1.2 \mathrm{~kg} / \mathrm{m}^{3}$ of henna extract). It was observed that the corrosion inhibition increased with the henna extract concentration. On the contrary, it decreased with a rise in temperature. The corrosion rate decreased on the steel coupons after the application of henna extract as the concentration increased, and it increased with a rise in temperature. The corrosion rate was reduced compared to that of $\mathrm{HCl}$ in the material with no corrosion inhibitor $\left(1.9 \times 10^{-9} \mathrm{~m} / \mathrm{s}\right.$ at $298.15 \mathrm{~K}$ in $\left.3.1 \% \mathrm{HCl}\right)$. The lowest corrosion rate recorded was $3.9 \times 10^{-7} \mathrm{~m} / \mathrm{s}$ at a temperature of $298.15 \mathrm{~K}$ and at a concentration of $1.2 \mathrm{~kg} / \mathrm{m}^{3}$ of henna, which is an IE\% of $92.59 \%$. This result occurred at both the lowest temperature and the highest concentration tested in the experimental 
study. On the contrary, the highest corrosion rate of $5.2 \times 10^{-9} \mathrm{~m} / \mathrm{s}$ occurred at $333.15 \mathrm{~K}$ and a henna concentration of $0.2 \mathrm{~kg} / \mathrm{m}^{3}$. These are both the highest temperature and the lowest concentration tested. Hence, henna extract was not successful at high temperatures and low concentrations. In Table 3, SEM images in the absence and presence of henna extract after immersion in $\mathrm{HCl}$ are shown, which show the notorious pitting tendency of $\mathrm{HCl}$ before the application of henna extract. After the application of henna extract, the pits disappear and the steel coupon surface is almost free from corrosion.

\subsubsection{Aqueous Garlic Peel Extract}

Most inhibitors that are used in the industry are organic compounds that contain oxygen, nitrogen, or sulfur atoms. It was discovered that when garlic cloves are distilled in water, garlic oil is isolated, which contains a mixture of compounds including diallyl sulfide, trisulfide, and polysulfide, which are all compounds of organosulfur [70]. An experimental study [71] investigated the inhibitory capability of garlic peel extract (aqueous garlic peel extract) on C-steel after $24 \mathrm{~h}$ of immersion in $3.1 \% \mathrm{HCl}$ at different concentrations $\left(0.001-1 \mathrm{~kg} / \mathrm{m}^{3}\right)$ of aqueous garlic peel. They also tested this inhibitor at different temperatures (298.15-328.15 K) using the same concentration of $0.4 \mathrm{~kg} / \mathrm{m}^{3}$ of aqueous garlic peel extract. In the absence of the corrosion inhibitor, the corrosion rate was $7.1 \times 10^{-9} \mathrm{~m} / \mathrm{s}$ at $298.15 \mathrm{~K}$ in $3.1 \% \mathrm{HCl}$. Using weight loss measurements, the lowest corrosion rate of $2.3 \times 10^{-10} \mathrm{~m} / \mathrm{s}$ was achieved at $298.15 \mathrm{~K}$. This resulted in an IE\% of $96.7 \%$. Interestingly, the IE\% increased with the temperature, going from $69 \%$ to $83 \%$ when the temperature increased from 298.1 to $328.15 \mathrm{~K}$. The IE\% increased with the concentration of the inhibitor, having the highest IE $\%$ at $1 \mathrm{~kg} / \mathrm{m}^{3}$ of garlic extract, but the study decided that it was still efficient at a concentration of $0.4 \mathrm{~kg} / \mathrm{m}^{3}$. The SEM micrographs of this experiment can be found in Table 3. They were done on C-steel after being immersed in $3.1 \% \mathrm{HCl}$ in the absence and presence of $0.4 \mathrm{~kg} / \mathrm{m}^{3}$ of aqueous garlic peel extract. It can be observed that in the absence of the corrosion inhibitor, the surface is rough and the pits resulting from the use of $\mathrm{HCl}$ are highly visible. After the corrosion inhibitor, the surface is much smoother, and the pits are almost completely gone. This was attributed to a strong chemisorptive bond between the organosulfur compounds and the C-steel surface, which was detected on the Scanning Electron Microscopy with Energy Dispersive X-ray Spectroscopy (SEM/EDX) analysis. 
Table 3. Corrosion rates (CR) of different corrosion inhibitors (CI) tested at various inhibitor concentrations (IC), $\mathrm{HCl}$ concentrations on carbon steel materials.

\begin{tabular}{|c|c|c|c|c|c|c|c|c|c|c|}
\hline Inhibitor & $\begin{array}{c}\text { Inhibitor } \\
\text { Type }\end{array}$ & $\begin{array}{l}\mathrm{HCl} \\
(\%)\end{array}$ & $\mathrm{T}(\mathrm{K})$ & Material & $\begin{array}{l}\text { Opt. I.C. } \\
\left(\mathbf{k g} / \mathrm{m}^{3}\right)\end{array}$ & $\begin{array}{c}\text { CR Blank } \\
(\mathrm{m} / \mathrm{s})\end{array}$ & $\underset{(\mathrm{m} / \mathrm{s})}{\mathrm{CR} \text { after }}$ & $\begin{array}{c}\text { Material with No } \\
\text { CI }\end{array}$ & $\begin{array}{l}\text { Material after } \\
\text { CI }\end{array}$ & Reference \\
\hline $\begin{array}{l}\text { Propargyl } \\
\text { alcohol }\end{array}$ & \multirow{3}{*}{ Organic } & 15 & 373.15 & $\begin{array}{c}\text { MS (C } 0.14 \% \text {, } \\
\text { Mn 0.25\%, Si } \\
0.17 \%, \mathrm{P} \\
0.03 \%, \mathrm{Fe})\end{array}$ & 5 & $3.9 \times 10^{-7}$ & $1.2 \times 10^{-9}$ & N/A & N/A & [56] \\
\hline $\begin{array}{l}\text { Furfuryl } \\
\text { alcohol }\end{array}$ & & 15 & 303.15 & $\begin{array}{c}\text { N80 (C } 0.31 \% \text {, } \\
\text { S } 0.008 \%, \mathrm{P} \\
0.01 \%, \mathrm{Si} \\
0.19 \%, \mathrm{Mn} \\
0.92 \%, \mathrm{Cr} \\
0.20 \%, \mathrm{Fe})\end{array}$ & 15.7 & $1.5 \times 10^{-8}$ & $1.5 \times 10^{-9}$ & & & [45] \\
\hline QMQTPH & & 3.1 & 303.15 & $\begin{array}{c}\text { MS (C } 0.18 \% \text {, } \\
\text { Mn 0.6\%, S } \\
0.05 \%, \mathrm{P} \\
0.04 \% \text {, Si } \\
0.1 \%, \mathrm{Fe})\end{array}$ & 0.5 & $5.0 \times 10^{-10}$ & $3.5 \times 10^{-11}$ & & & [53] \\
\hline $\begin{array}{l}\text { Henna } \\
\text { extract }\end{array}$ & \multirow{2}{*}{$\begin{array}{l}\text { Natural } \\
\text { extract }\end{array}$} & 3.1 & 298.15 & $\begin{array}{c}\text { MS (C } \\
0.179 \%, \mathrm{Si} \\
0.165 \%, \mathrm{Mn} \\
0.439 \%, \mathrm{Cu} \\
0.203 \%, \mathrm{~S} \\
0.034 \%, \mathrm{Fe})\end{array}$ & 1.2 & $1.9 \times 10^{-9}$ & $1.4 \times 10^{-10}$ & & 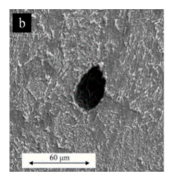 & [67] \\
\hline $\begin{array}{l}\text { Aqueous } \\
\text { garlic peel } \\
\text { extract }\end{array}$ & & 3.1 & 298.15 & $\begin{array}{c}\text { C-steel (C } \\
0.18 \%, \text { P 0.04 } \\
\%, \text { S 0.05\%, } \\
\text { Mn 0.30\%, } \\
\text { trace Si, Fe) }\end{array}$ & 0.4 & $7.1 \times 10^{-9}$ & $2.3 \times 10^{-10}$ & & & [71] \\
\hline
\end{tabular}

All of the experiments discussed were successful in lowering $\mathrm{HCl}^{\prime}$ s corrosion rate on the samples. It can be noted that the lowest corrosion rate was achieved by QMQTPH $\left(3.5 \times 10^{-11} \mathrm{~m} / \mathrm{s}\right.$ at $303.15 \mathrm{~K}$ in $\left.3.1 \% \mathrm{HCl}\right)$. Henna extract has the next lowest corrosion rate, but it was achieved at more than twice the concentration of quinoline. Garlic peel extract also achieved successful corrosion inhibition, and at an even lower concentration than QMQTPH. All these corrosion rates are lower than that of furfuryl alcohol, which is one of the most used organic corrosion inhibitors. Natural occurring substances as corrosion inhibitors are shown to be good alternatives to common organic and inorganic corrosion inhibitors in the sense that they are more environmentally acceptable and can be a renewable resource for their use. In the case of henna extract, it was observed that it worked at very high concentrations, but its concentration was still lower than that of furfuryl alcohol. The need for new corrosion inhibitors that provide comparable effectiveness to that of organic corrosion inhibitors that are, at the same time, not detrimental to the environment is highly desired. 


\section{Conclusions}

For the high-temperature conditions:

- It has been observed that the use of $\mathrm{HCl}$ is not the best option in high-temperature environments since its high reaction rates with the rock in the formation require higher acid volumes to provide effective stimulation to the formation. Therefore, the use of retarded acid systems has been found successful in this area.

- The use of nonionic surfactants (especially highly ethoxylated compounds) that provide effective reaction retardation because of their ability to viscosify the fluid is very beneficial. Their use has also resulted in the production of effective and dominant wormholes in core flood tests of recent experimental studies.

- The study of nonylphenol as a nonionic surfactant in acid systems at high-temperature conditions would be an interesting and promising area of research that could most likely provide successful results in matrix acidizing treatments because of its positive results at $298.15 \mathrm{~K}$ in previous studies.

For the heterogenous formations:

- $\quad \mathrm{HCl}$ by itself tends to flow through the most permeable zone of the formation when injected, leaving the low-permeability zones untreated. This is detrimental to the formations that have high heterogeneity. The use of diverters has been found very helpful in this aspect since their main purpose is to direct the acid to temporarily plug the high-permeability (thief) zones, thus making the acid flow through the less-permeable zones.

- In this matter, the use of viscoelastic surfactants (VES) has been found outstanding in the diversion aspect, especially because they do not have any polymer content, and thus are less susceptible to causing damage after their use. In addition, the new foam-based VES system has promising results even at a permeability contrast of 15. However, the use of a polymer-assisted emulsified acid was found to be more successful than the latter at a permeability contrast of 19 , which is a higher KR than the optimal one for foam-based VES systems.

- $\quad$ The use of foam acid has been found to be helpful in diverting the acid to the lowpermeability areas, but only at permeability contrasts lower than 7.8 , which means that their use is very limited in heterogeneous formations.

For the corrosive environments:

- Corrosion represents a large part of the total cost of acid treatments per year since $\mathrm{HCl}$ has been found to have a pitting tendency on steel (which is the main material used in acid treatments), which is worsened with an increase in temperature.

- The use of inorganic corrosion inhibitors like arsenic and antimony has been limited due to their high toxicity, human health concerns, and environmental pollution. The use of organic compounds, especially the use of acetylenic compounds like propargyl alcohol and thiourea derivatives, which have high efficiency, has also been slowed down to their being non-biodegradable, which has worried several environmental organizations.

- Greener corrosion inhibitors are necessary for acidizing treatments. The use of aqueous garlic peel extract was shown to have successful corrosion inhibition in acid treatments.

Author Contributions: Conceptualization, M.P.; methodology, M.P.; validation, O.G.C.; formal analysis, O.G.C.; investigation, O.G.C.; resources, O.G.C.; data curation, O.G.C.; writing-original draft preparation, O.G.C.; writing-review and editing, M.P.; visualization, O.G.C.; supervision, M.P.; project administration, M.P.; funding acquisition, O.G.C. and M.P. All authors have read and agreed to the published version of the manuscript.

Funding: We thank UTRGV Career Center for providing financial support to Ofelia Gomez Chacon through the Student Experience Internship (SEI) program. This research did not receive any external funding. 


\section{Institutional Review Board Statement: Not applicable.}

Informed Consent Statement: Not applicable.

Conflicts of Interest: The authors declare no conflict of interest.

\section{References}

1. Rae, P.; Di Lullo, G. Matrix Acid Stimulation-A Review of the State-Of-The-Art. In Proceedings of the SPE European Formation Damage Conference, The Hague, The Netherlands, 13-14 May 2003. [CrossRef]

2. Fredd, C.N.; Fogler, H.S. Alternative Stimulation Fluids and Their Impact on Carbonate Acidizing. In Proceedings of the SPE Formation Damage Control Symposium, Lafayette, LA, USA, 14-15 February 1996. [CrossRef]

3. Garrouch, A.A.; Jennings, A.R., Jr. A contemporary approach to carbonate matrix acidizing. J. Pet. Sci. Eng. 2017, 158, 129-143. [CrossRef]

4. Sokhanvarian, K.; Stanciu, C.; Fernandez, J.M.; Ibrahim, A.; Nasr-El-Din, H.A. Novel non-aromatic polymer-ionic surfactants to target deep carbonate stimulation. In Proceedings of the SPE International Conference on Oilfield Chemistry, Galveston, TX, USA, 8-9 April 2019. [CrossRef]

5. Wang, Y.; Hill, A.D.; Schechter, R.S. The optimum injection rate for matrix acidizing of carbonate formations. In Proceedings of the SPE Annual Technical Conference and Exhibition, Houston, TX, USA, 3-6 October 1993.

6. Fredd, C.N.; Fogler, H.S. Optimum conditions for wormhole formation in carbonate porous media: Influence of transport and reaction. Spe J. 1999, 4, 196-205. [CrossRef]

7. Bazin, B.; Abdulahad, G. Experimental investigation of some properties of emulsified acid systems for stimulation of carbonate formations. In Proceedings of the Middle East Oil Show and Conference, Manama, Bahrain, 20-23 February 1999.

8. Huang, T.; Ostensen, L.; Hill, A.D. Carbonate matrix acidizing with acetic acid. In Proceedings of the SPE International Symposium on Formation Damage Control, Lafayette, LA, USA, 23-24 February 2000.

9. Perez, T.E. Corrosion in the oil and gas industry: An increasing challenge for materials. Jom 2013, 65, 1033-1042. [CrossRef]

10. Quraishi, M.A.; Chauhan, D.S.; Ansari, F.A. Development of environmentally benign corrosion inhibitors for organic acid environments for oil-gas industry. J. Mol. Liq. 2021, 329, 115514. [CrossRef]

11. Ashter, S.A. Thermoforming of Single and Multilayer Laminates: Plastic Films Technologies, Testing, and Applications; William Andrew: Norwich, NY, USA, 2013.

12. Ortega, A. Acidizing High-Temperature Carbonate Formations Using Methanesulfonic Acid; Texas A\&M University: College Station, TX, USA, 2015.

13. Ibrahim, A.F.; Nasr-El-Din, H.; Jiang, L. HP/HT Matrix Acidizing Treatments of Carbonate Rocks Using A New Retarded HCl Acid System. In Proceedings of the International Petroleum Technology Conference, Dhahran, Saudi Arabia, 13-15 January 2020. [CrossRef]

14. Noshi, C.I. A Novel In-Situ Generated Acid System on Carbonate Mineral Dissolution in Sandstone Reservoirs. Ph.D. Thesis, Texas A\&M University, College Station, TX, USA, December 2005.

15. Huang, T.; McElfresh, P.M.; Gabrysch, A.D. Carbonate matrix acidizing fluids at high temperatures: Acetic Acid, chelating agents or Long-Chained carboxylic acids? In Proceedings of the SPE European Formation Damage Conference, The Hague, The Netherlands, 13-14 May 2003. [CrossRef]

16. Buijse, M.; de Boer, P.; Breukel, B.; Burgos, G. Organic acids in carbonate acidizing. SPE Prod. Facil. 2004, 19, 128-134. [CrossRef]

17. Pandey, J.S.; Nazari, N.; Thomsen, K.; Barati, R. A novel Equipment-Friendly and Environment-friendly WELL Stimulation fluid for Carbonate Reservoirs: Better wormholes and Lower corrosion at Reservoir Conditions. In Proceedings of the SPE International Conference and Exhibition on Formation Damage Control, Lafayette, LA, USA, 7-9 February 2018. [CrossRef]

18. Shank, R.A.; McCartney, T.R. Synergistic and Divergent Effects of Surfactants on the Kinetics of Acid Dissolution of Calcium Carbonate Scale. In Proceedings of the CORROSION 2013, Orlando, FL, USA, 17-21 March 2013.

19. Zakaria, A.S.; Nasr-El-Din, H.A. A novel polymer-assisted emulsified-acid system improves the efficiency of carbonate matrix acidizing. SPE J. 2016, 21, 1061-1074. [CrossRef]

20. Rodrigues, M.A.; Arruda, G.M.; Da Silva, D.C.; Da Costa, F.M.; De Brito, M.F.; Antonino, A.C.; Wanderley Neto, A.D. Application of nonionic surfactant nonylphenol to control acid stimulation in carbonate matrix. J. Pet. Sci. Eng. 2021, 203, 108654. [CrossRef]

21. Gomaa, A.M.; Nasr-El-Din, H.A. Effect of elastic properties on the propagation of gelled and in-situ gelled acids in carbonate cores. J. Pet. Sci. Eng. 2015, 127, 101-108. [CrossRef]

22. Correia, M.G.; Maschio, C.; Schiozer, D.J. Integration of multiscale carbonate reservoir heterogeneities in reservoir simulation. J. Pet. Sci. Eng. 2015, 131, 34-50. [CrossRef]

23. Pal, S.; Mushtaq, M.; Banat, F.; Al Sumaiti, A.M. Review of surfactant-assisted chemical enhanced oil recovery for carbonate reservoirs: Challenges and future perspectives. Pet. Sci. 2018, 15, 77-102. [CrossRef]

24. Li, Y.; Deng, Q.; Zhao, J.; Liao, Y.; Jiang, Y. Simulation and analysis of matrix stimulation by diverting acid system considering temperature field. J. Pet. Sci. Eng. 2018, 170, 932-944. [CrossRef]

25. Gomaa, A.M.M. Acid Diversion in Carbonate Reservoirs Using Polymer-Based In-Situ Gelled Acids. Ph.D. Dissertation, Texas A\&M University, College Station, TX, USA, May 2011. 
26. Wei, B. Evaluation of Preformed Particle Gel as a Diverting Agent for Acidizing; Missouri University of Science and Technology: Rolla, MO, USA, 2017

27. Cao, C.; Zhou, F.; Cheng, L.; Liu, S.; Lu, W.; Wang, Q. A comprehensive method for acid diversion performance evaluation in strongly Heterogeneous Carbonate reservoirs stimulation using CT. J. Pet. Sci. Eng. 2021, 203, 108614. [CrossRef]

28. Al-Anazi, H.A.; Nasr-El-Din, H.A.; Mohamed, S.K. Stimulation of tight carbonate reservoirs using acid-in-diesel emulsions: Field application. In Proceedings of the SPE Formation Damage Control Conference, Lafayette, LA, USA, 18-19 February 1998.

29. Nasr-El-Din, H.A.; Al-Anazi, H.A.; Mohamed, S.K. Stimulation of water-disposal wells using acid-in-diesel emulsions: Case histories. SPE Prod. Facil. 2000, 15, 176-182. [CrossRef]

30. Madyanova, M.; Hezmela, R.; Artola, P.; Guimaraes, C.R.; Iriyanto, B. Effective matrix stimulation of high-temperature carbonate formations in south Sumatra through the combination of emulsified and viscoelastic self-diverting acids. In Proceedings of the SPE International Symposium and Exhibition on Formation Damage Control, Lafayette, LA, USA, 15-17 February 2012.

31. Czupski, M.; Kasza, P.; Leśniak, Ł. Development of selective acidizing technology for an oil field in the Zechstein Main Dolomite Energies 2020, 13, 5940. [CrossRef]

32. Finšgar, M.; Jackson, J. Application of corrosion inhibitors for steels in acidic media for the oil and gas industry: A review. Corros. Sci. 2014, 86, 17-41. [CrossRef]

33. Ali, S.; Reyes, J.S.; Samuel, M.M.; Auzerais, F.M. Self-Diverting Acid Treatment with Formic-Acid-Free Corrosion Inhibitor U.S. Patent 7,902,124, 8 March 2011.

34. de Queiroz Baddini, A.L.; Cardoso, S.P.; Hollauer, E.; Gomes, J.A.D.C.P. Statistical analysis of a corrosion inhibitor family on three steel surfaces (duplex, super-13 and carbon) in hydrochloric acid solutions. Electrochim. Acta 2007, 53, 434-446. [CrossRef]

35. Hill, D.G.; Romijn, H. Reduction of risk to the marine environment from oilfield chemicals: Environmentally improved acid corrosion inhibition for well stimulation, Corrosion. In Proceedings of the CORROSION 2000, Orlando, FL, USA, $26-31$ March 2000.

36. Panossian, Z.; de Almeida, N.L.; de Sousa, R.M.F.; de Souza Pimenta, G.; Marques, L.B.S. Corrosion of carbon steel pipes and tanks by concentrated sulfuric acid: A review. Corros. Sci. 2012, 58, 1-11. [CrossRef]

37. Durnie, W.; De Marco, R.; Jefferson, A.; Kinsella, B. Development of a Structure-Activity Relationship for Oil Field Corrosion Inhibitors. J. Electrochem. Soc. 1999, 146, 1751-1756. [CrossRef]

38. Torres-Islas, A.; Serna, S.; Uruchurtu, J.; Campillo, B.; González-Rodríguez, J.G. Corrosion inhibition efficiency study in a microalloyed steel for sour service at $50{ }^{\circ} \mathrm{C}$. J. Appl. Electrochem. 2010, 40, 1483-1491. [CrossRef]

39. Brondel, D.; Edwards, R.; Hayman, A.; Hill, D.; Mehta, S.; Semerad, T. Corrosion in the oil industry. Oilfield Rev. 1994, 6, 4-18.

40. Singh, A.; Quraishi, M.A. Acidizing corrosion inhibitors: A review. J. Mater. Environ. Sci. 2015, 6, $224-235$.

41. Annand, R.R.; Hurd, R.M.; Hackerman, N. Adsorption of monomeric and polymeric amino corrosion inhibitors on steel. J. Electrochem. Soc. 1965, 112, 138. [CrossRef]

42. Cotton, J.B.; Scholes, I.R. Benzotriazole and related compounds as corrosion inhibitors for copper. Br. Corros. J. 1967, 2, 1-5. [CrossRef]

43. Talati, J.D.; Gandhi, D.K. N-heterocyclic compounds as corrosion inhibitors for aluminium-copper alloy in hydrochloric acid. Corros. Sci. 1983, 23, 1315-1332. [CrossRef]

44. Popova, A.; Christov, M. Evaluation of impedance measurements on mild steel corrosion in acid media in the presence of heterocyclic compounds. Corros. Sci. 2006, 48, 3208-3221. [CrossRef]

45. Vishwanatham, S.; Haldar, N. Furfuryl alcohol as corrosion inhibitor for N80 steel in hydrochloric acid. Corros. Sci. 2008, 50, 2999-3004. [CrossRef]

46. Popova, A.; Sokolova, E.; Raicheva, S.; Christov, M. AC and DC study of the temperature effect on mild steel corrosion in acid media in the presence of benzimidazole derivatives. Corros. Sci. 2003, 45, 33-58. [CrossRef]

47. Ita, B.I.; Offiong, O.E. The inhibition of mild steel corrosion in hydrochloric acid by $2,2^{\prime}$-pyridil and a-pyridoin. Mater. Chem. Phys. 1997, 51, 203-210. [CrossRef]

48. el Rehim, S.S.A.; Ibrahim, M.A.M.; Khalid, K.F. The inhibition of 4-(20-amino-50-methylphenylazo) antipyrine on corrosion of mild steel in $\mathrm{HCl}$ solution. Mater. Chem. Phys. 2001, 70, 268-273. [CrossRef]

49. Quraishi, M.; Jamal, D. Fatty acid triazoles: Novel corrosion inhibitors for oil well steel (N-80) and mild steel. J. Am. Oil Chem. Soc. 2000, 77, 1107-1111. [CrossRef]

50. Quraishi, M.A.; Jamal, D.; Singh, R.N. Inhibition of mild steel corrosion in the presence of fatty acid thiosemicarbazides. Corrosion 2000, 58, 201-207. [CrossRef]

51. Aljourani, J.; Raeissi, K.; Golozar, M.A. Benzimidazole and its derivatives as corrosion inhibitors for mild steel in $1 \mathrm{M} \mathrm{HCl} \mathrm{solution.}$ Corros. Sci. 2009, 51, 1836-1843. [CrossRef]

52. Tang, L.; Li, X.; Li, L.; Qu, Q.; Mu, G.; Liu, G. The effect of 1-(2-pyridylazo)-2-naphthol on the corrosion of cold rolled steel in acid media: Part 1: Inhibitive action in 1.0 M hydrochloric acid. Mater. Chem. Phys. 2005, 94, 353-359. [CrossRef]

53. Saliyan, V.R.; Adhikari, A.V. Quinolin-5-ylmethylene-3-\{[8-(trifluoromethyl)quinolin-4-yl]thio\}propanohydrazide as an effective inhibitor of mild steel corrosion in $\mathrm{HCl}$ solution. Corros. Sci. 2008, 50, 55-61. [CrossRef]

54. Salarvand, Z.; Amirnasr, M.; Talebian, M.; Raeissi, K.; Meghdadi, S. Enhanced corrosion resistance of mild steel in $1 \mathrm{M} \mathrm{HCl}$ solution by trace amount of 2-phenyl-benzothiazole derivatives: Experimental, quantum chemical calculations and molecular dynamics (MD) simulation studies. Corros. Sci. 2017, 114, 133-145. [CrossRef] 
55. Barmatov, E.; Geddes, J.; Hughes, T.; Nagl, M. Research on corrosion inhibitors for acid stimulation. In Proceedings of the CORROSION 2012, Salt Lake City, UT, USA, 11-15 March 2012.

56. Quraishi, M.A.; Ahmad, M.A.S.; Venkatachari, G. Synergistic effect of 2-amino-6-chloro-benzothiazole on inhibitive performance of propargyl alcohol during corrosion of mild steel in boiling hydrochloric acid solution. Bull. Electrochem. 1997, 13, $257-259$.

57. Bentiss, F.; Lebrini, M.; Lagrenee, M. Thermodynamic characterization of metal dissolution and inhibitor adsorption processes in mild steel/2, 5-bis (n-thienyl)-1, 3, 4-thiadiazoles/hydrochloric acid system. Corros. Sci. 2005, 47, 2915-2931. [CrossRef]

58. Khaled, K.F.; Babić-Samardžija, K.; Hackerman, N. Theoretical study of the structural effects of polymethylene amines on corrosion inhibition of iron in acid solutions. Electrochim. Acta 2005, 50, 2515-2520. [CrossRef]

59. Wang, H.L.; Liu, R.B.; Xin, J. Inhibiting effects of some mercapto-triazole derivatives on the corrosion of mild steel in $1.0 \mathrm{M} \mathrm{HCl}$ medium. Corros. Sci. 2004, 46, 2455-2466. [CrossRef]

60. Abd El-Rehim, S.S.; Ibrahim, M.A.; Khaled, K.F. 4-Aminoantipyrine as an inhibitor of mild steel corrosion in $\mathrm{HCl}$ solution J. Appl. Electrochem. 1999, 29, 593-599. [CrossRef]

61. Sibel, Z.O.R.; Doğan, P. Inhibition of acidic corrosion of iron and aluminium by SDBS at different temperatures. Corros. Rev. 2005, 23, 217-232.

62. Emregül, K.C.; Kurtaran, R.; Atakol, O. An investigation of chloride-substituted Schiff bases as corrosion inhibitors for steel. Corros. Sci. 2003, 45, 2803-2817. [CrossRef]

63. Rengamani, S.; Muralidharan, S.; Kulandainathan, M.A.; Iyer, S.V. Inhibiting and accelerating effects of aminophenols on the corrosion and permeation of hydrogen through mild steel in acidic solutions. J. Appl. Electrochem. 1994, 24, 355-360. [CrossRef]

64. Quraishi, M.A.; Jamal, D. Inhibition of mild steel corrosion in the presence of fatty acid triazoles. J. Appl. Electrochem. 2002, 32, 425-430. [CrossRef]

65. Williams, D.A.; Holifield, P.K.; Looney, J.R.; McDougall, L.A. Corrosion Inhibitor and Method of Use. U.S. Patent 5,002,673, 26 March 1991.

66. Fourth North Sea Ministerial Declaration. Fourth North Sea Ministerial Declaration I International Environmental Agreements (IEA) Database Project. Available online: https://iea.uoregon.edu/treaty-text/3926 (accessed on 15 December 2021).

67. Ostovari, A.; Hoseinieh, S.M.; Peikari, M.; Shadizadeh, S.R.; Hashemi, S.J. Corrosion inhibition of mild steel in $1 \mathrm{M} \mathrm{HCl}$ solution by henna extract: A comparative study of the inhibition by henna and its constituents (Lawsone, Gallic acid, a-D-Glucose and Tannic acid). Corros. Sci. 2009, 51, 1935-1949. [CrossRef]

68. Satapathy, A.K.; Gunasekaran, G.; Sahoo, S.C.; Amit, K.; Rodrigues, P.V. Corrosion inhibition by Justicia gendarussa plant extract in hydrochloric acid solution. Corros. Sci. 2009, 51, 2848-2856. [CrossRef]

69. Ashassi-Sorkhabi, H.; Majidi, M.R.; Seyyedi, K. Investigation of inhibition effect of some amino acids against steel corrosion in $\mathrm{HCl}$ solution. Appl. Surf. Sci. 2004, 225, 176-185. [CrossRef]

70. Parikh, K.S.; Joshi, K.J. Natural compounds onion, garlic and bitter gourd as corrosion inhibitors for mild steel in hydrochloric acid. Trans. SAEST 2004, 39, 29-35.

71. Pereira, S.S.D.A.A.; Pegas, M.M.; Fernandez, T.L.; Magalhaes, M.; Schöntag, T.G.; Lago, D.C.; D’Elia, E. Inhibitory action of aqueous garlic peel extract on the corrosion of carbon steel in $\mathrm{HCl}$ solution. Corros. Sci. 2012, 65, 360-366. [CrossRef] 